\title{
Tratamento de Fratura Le Fort I em paciente jovem: relato de caso
}

Treatment of a Le Fort I fracture in young patient: case report

Tratamiento de Fractura Le Fort I en paciente joven: relato de caso

\author{
Gabriel MULINARI-SANTOS \\ Breno dos Reis FERNANDES \\ Bruno Coelho MENDES \\ Sormani Bento Fernandes de QUEIROZ \\ Juliana Zorzi COLÉTE \\ Francisley Ávila SOUZA \\ Idelmo Rangel GARCIA JÚNIOR \\ Programa de Pós-Graduação em Odontologia, Faculdade de Odontologia de Araçatuba, UNESP - Univ Estadual Paulista "Júlio de Mesquita Filho" \\ 16015-050 Araçatuba-SP, Brasil
}

\section{Resumo}

Em seu estudo, René Le Fort caracterizou três tipos de padrões fratura: Le Fort I, II e III. Na Le Fort I, observou um traço de fratura transverso na maxila acima do ápice dos dentes. Com o aumento da força de intensidade nos traumas, os três padrões de fratura Le Fort, são cada vez mais improváveis de acontecer de forma isolada. Com isso, este trabalho tem como objetivo apresentar um caso clínico de uma fratura do tipo Le Fort I em um paciente jovem, tratada com placas de titânio nos pilares caninos e zigomáticos da maxila.

Descritores: Traumatologia; Maxila; Fixação de Fratura.

\section{Abstract}

In his study, René Le Fort characterized three types of fracture patterns: Le Fort I, II and III. At Le Fort I, he observed a trace of transverse fracture in the maxilla above the apex of the teeth. With increased strength of intensity in traumas, the three Le Fort fracture patterns are increasingly unlikely to occur in isolation. The aim of this study is to present a case report of a Le Fort I type fracture in a young patient, treated with titanium plates in the canine and zygomatic maxillary pillars.

Descriptors: Traumatology; Maxilla; Fracture Fixation.

\section{Resumen}

En su estudio, René Le Fort caracterizó tres tipos de patrones fractura: Le Fort I, II y III. En la Le Fort I, observó un trazo de fractura transverso en la mandíbula encima del ápice de los dientes. Con el aumento de la fuerza de intensidad en los traumas, los tres patrones de fractura Le Fort, son cada vez más improbables de suceder de forma aislada. Con ello, este trabajo tiene como obj etivo presentar un caso clínico de una fractura del tipo Le Fort I en un paciente joven, tratada con placas de titanio en los pilares caninos y zigomáticos de la mandíbula.

Descriptores: Traumatología; Maxilar; Fijación de Fractura.

\section{INTRODUÇÃO}

A fratura de Le Fort I é também conhecida como fratura de Guerín ${ }^{1,2}$. O traço de fratura ocorre de forma transversa na maxila, acima do ápice dos dentes. Já as fraturas Le Fort II abrangem fraturas da maxila, região nasoetmoidal e piramidal. Por último, as fraturas Le Fort III referem-se a uma disjunção óssea craniofacial, ou seja, a separação entre os ossos do crânio e da face ${ }^{1,2}$.

René Le Fort definiu os padrões de fraturas por meio de um estudo experimental realizado em crânios de cadáveres ${ }^{3}$. Nesse estudo, observou que o padrão de fratura Le Fort I acometia parede anterior, lateral até posterior de terceiro molar do osso da maxila, com a separação da placa pterigoide ${ }^{3}$. Além disso, nos três padrões de fratura Le Fort, a única coincidência descrita foi a presença da fratura pterigoide bilateral $^{3,4}$.

Cada padrão de fratura Le Fort tem no mínimo um componente único característico daquela fratura $^{5}$. Essas características são facilmente reconhecidas no exame clinico dos pacientes traumatizados, sendo possível distinguir os padrões de fratura Le Fort ${ }^{6}$. A peculiaridade da fratura Le Fort I são os sinais de fratura envolvendo somente ossos do palato e da maxila ${ }^{6}$.

Assim, o objetivo desse trabalho é relatar o tratamento de um caso clínico de fratura do tipo Le Fort I em um paciente jovem.

\section{CASO CLÍNICO}

Paciente, gênero masculino, 17 anos de idade, atendido na Santa Casa de Misericórdia de Araçatuba após ser vítima de acidente motociclístico, negando comorbidades, alergias e uso de medicamentos, apresentando ao exame físico: mobilidade de maxila, hiposfagma, edema e equimose periorbitária esquerda, não observando alteração nos movimentos oculares ou qualquer limitação de abertura bucal (Figura 1A).

Ao exame de imagem, por imeio da tomografia computadorizada em cortes coronal, axial e reconstrução pode-se constatar traço sugestivo de fratura Le Fort I com envolvimento dos pilares caninos e zigomáticos (Figura 1B). Após o exame clínico e imaginológico diagnosticou-se a fratura Le Fort I da maxila.

O tratamento cirúrgico foi realizado sob anestesia geral, entubação nasotraqueal. Foi realizado acesso vestibular intrabucal para exposição da fratura em pilares zigomáticos e caninos (Figura 1C).

Após realização do reposicionamento redução da fratura nos pilares caninos e zigomáticos, optou-se pela fixação interna rígida. Para os pilares zigomáticos foi utilizadas placas em "L" de 4 furos com intermediário e parafusos do sistema 2.0, nos pilares caninos foi empregada placa de 4 furos com intermediário e parafusos do sistema 1.5 (Figura 1D).

No pós-operatório de 15 dias observou-se 
edema compatível com o procedimento cirúrgico, suturas e curativos em posição e ausência de sinais de sintomas de infecção local, e também relato de oclusão estável, ausência de diplopias pelo paciente. $\mathrm{Na}$ tomografia computadorizada em reconstrução tridimensional, placas e parafusos com alinhamento dos segmentos fraturados (Figura 1E).

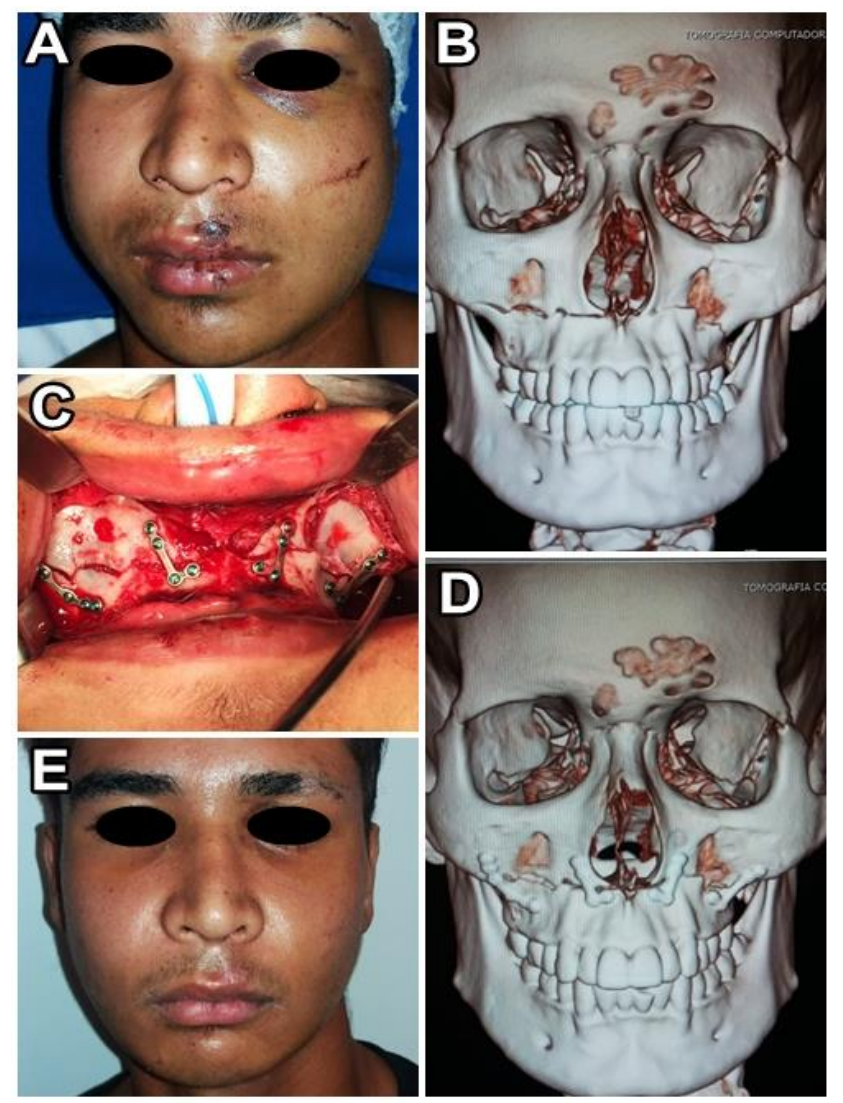

Figura 1: A. Pré-operatório. No o exame físico mobilidade de maxila, hiposfagma, edema e equimose periorbitária esquerda. B. Tomografia computadorizada em reconstrução tridimensional evidenciando o traço de fratura padrão Le Fort I em maxila, acima do ápice dos dentes superiores. C. Transoperatório. Acesso vestibular em fundo de fórnix vestibular e posicionamento das placas de titânio para fixação da fratura. D. Tomografia computadorizada em reconstrução tridimensional evidenciando o a fixação da fratura padrão Le Fort I em maxila. E. Pósoperatório. Após 15 dias, observou-se adequado restabelecimento estético e funcional do paciente.

DISCUSSÃO

Impactos anteriores causam padrões recorrentes de fratura que seguem as três linhas de fraqueza no esqueleto facial, descritas por Le Fort em $1901^{3,4}$. A fratura Le Fort I também chamada de Guérin ocorre no sentido transverso da maxila, acima do ápice dos dentes ${ }^{3,4}$. Já a Le Fort II ocorre com fratura da maxila e regiões nasoetmoidal e piramidal $^{3,4}$. Le Fort III refere-se a fratura na disjunção óssea craniofacial ${ }^{3,4}$.

Como as forças de impacto geralmente não são perfeitamente localizadas, as fraturas do tipo Le Fort I podem ocorrer em combinações imprevisíveis ${ }^{7,8}$. Usualmente, as fraturas têm padrões assimétricos, variando em fraturas isoladas e mínimas até fraturas múltiplas e deslocadas ${ }^{7,8}$. Porém, como tratamento todas as fraturas Le Fort I necessitam da redução e fixação da fratura nos pilares caninos e zigomáticos visando o restabelecimento estético e funcional ${ }^{9}$.

Em virtude do aumento da velocidade de veículos e motocicletas como do caso apresentado, as forças de impacto têm se tornadas mais intensas ${ }^{7}$. Sendo assim, os tipos de fratura Le Fort I são raros de acontecer atualmente. Dessa forma, é esperadas fraturas sem um padrão em seus traços com descrito pelo estudo de René Le Fort ${ }^{3,4}$. Dessa forma, a fratura Le Fort I do caso exposto pode ser considerada incomum nos dos dias de hoje.

\section{CONCLUSÃO}

Embora sejam menos comuns, as fraturas Le Fort I podem ocorrer nos dias de hoje. Como forma de tratamento, a fixação dos pilares caninos e zigomáticos mostram-se suficiente para obter um bom resultado estético e funcional ao paciente com esse padrão de fratura.

\section{REFERÊNCIAS}

1. Hupp JR, Ellis III E, Myron R. Cirurgia oral e maxilo facial-Tucker. 6. Ed; 2015.

2. Bailey BJ. Head and Neck SurgeryOtolaryngology. Philadelphia: JB Lippincott Company; 2001.

3. Tessier P. The classic reprint: experimental study of fractures of the upper jaw. I and II. René Le Fort, MD. Plast Reconstr Surg. 1972; 50(5):497-506.

4. Tessier P. The classic reprint: experimental study of fractures of the upper jaw. 3. René Le Fort, MD, Lille, France. Plast Reconstr Surg. 1972;50(6):600-7.

5. Cummings CW. Otolaryngology-Head and Neck Surgery. St. Louis, USA, Mosby Year Book,1993, vol. 1Philadelphia: JB Lippincott Company; 2001.

6. Miniti A. Bento,R.F. Butugan, O. ORL Clínica e cirúrgica. São Paulo: Atheneu; 1993.

7. Birolini D, Utiyama E, Steinman E. Cirurgia de Emergência. São Paulo, Atheneu; 1997.

8. Juhl JH. Crummy AB. Paul and Juhl's Essential of Radiologic Imaging; 1996.

9. Manson PN, Clark N, Robertson B, Slezak S, Wheatly M, Vander Kolk C et al. Subunit principles in midface fractures: the importance of sagittal buttresses, soft-tissue reductions, and sequencing treatment of segmental fractures. Plast Reconstr Surg. 1999;103(4):1287-306. 


\section{CONFLITO DE INTERESSES}

Os autores declaram não haver conflitos de interesse.

\section{AUTOR PARA CORRESPONDENCIA}

\section{Gabriel Mulinari dos Santos} gabriel_mulinari@hotmail.com

Submetido em 19/07/2018

Aceito em 04/10/2018 